Journal of Architectural Research and Development

Research Article

\title{
Research on Development and Construction of Characteristic Town
}

Tianyu Zhang

Jiangnan University, Wuxi 214122, Jiangsu Province, China

\begin{abstract}
Characteristic town is an innovative development model of urban-rural integration. These small towns with certain characteristics play an important role in China's economic transformation and urban-rural integration. Through literature search and field surveys, this article reports the existing theoretical achievements, including the conceptualization, significance of construction, and the research status of local/foreign characteristic towns. Besides, this article provides some practical suggestions towards the existing research problems and some reference for the planning and construction of characteristic towns.
\end{abstract}

Keywords: characteristic town, research and review, development status, countermeasures

Publication date: September, 2020

Publication online: 30 September, 2020

*Corresponding author: Zhang Tianyu, 313355797@ qq.com

\section{Introduction}

Since the Chinese economic reform, China's cities had experienced rapid development for more than 40 years. While the urbanization is advancing, many problems had emerged. With the exponential population growth and rapid expansion of urban, these had caused the deterioration to the environment and disappearance of low-cost labour and land resources. Simultaneously, with the continuous improvement of infrastructure construction, the geographical disadvantage of small towns is no longer a constraint to development, while the value of their landscape resources and special industries is constantly highlighted. Therefore, in the context of new urbanization, special attention had been focused on small towns.

Since the construction of characteristic towns in
Zhejiang Province started in 2015, characteristic towns have gradually gained people's attention, setting off a wave of construction. State ministries and commissions have issued relevant policy documents to guide the construction of characteristic small towns. The challenges of characteristic town constructions have also attracted the attention of the academic community. The study of the challenges faced in characteristic town constructions is a complex and huge project. Researching from different angles, scholars have enriched the theoretical basis of characteristic town construction. By combing through relevant literature, this article analyzes the connotation of a characteristic town, reviews the development and construction experience, and proposes countermeasures, expecting more in-depth research in future.

\section{Connotation and significance of a characteristic town}

\subsection{Connotation of a characteristic town}

The construction of characteristic towns was first succeeded in Zhejiang Province and recognized by the national leaders, and the Zhejiang experience was promoted nationwide. However, there are differences in the understanding of characteristic towns in various sectors of the societies. Therefore, the study of the connotation of the concept is crucial to the sustainable development of characteristic towns in future.

In the process of urbanization in Zhejiang Province, it has gradually formed massive economy as a feature, small and medium-sized towns as a spatial platform, and regional development characteristics of production and urban interaction ${ }^{[1]}$. As far as the whole country is concerned, the economic level of each province and the disparity between urban and rural development is large, and the primary consideration is to promote the 
integrated development of urban and rural areas and to develop small towns with special characteristics as one of the means of urbanization. Different perspectives are also reflected in defining the concept of a characteristic town: Zhejiang Province considers a characteristic town to be an innovative development platform that integrates industrialization, culture, tourism and socialization, which is distinctive from administrative and industrial units, while the national policy states that characteristic towns principally are the organizational towns. There is an obvious discrepancy between the two definitions of a characteristic town. To standardize the construction of special small towns and clarify their connotations, the state ministries and commissions have issued two articles emphasizing that characteristic small (city) towns include the two forms of characteristic small towns and characteristic small cities ${ }^{[2]}$. The definition achieves the separation of special small towns from the concept of special establishment small towns from the conceptual and theoretical level, which is of milestone importance for the development of characteristic towns in China.

Academics have also researched characteristic towns through different perspectives. According to Longbao Wei and others, a characteristic town is a practical and innovative result of exploring the development of new towns, with distinctive industrial characteristics, the combination of functions, small and exquisite space, flexible and innovative mechanisms, and other unique characteristics ${ }^{[3]}$. Xiaozhang Wang argued that the existing fundamental conditions and historical traditions are the prerequisites for the characteristic town construction. Also, the characteristic town is a regional community of social life, which is a unique form of life-based on the natural integration of people's living and ecological standards ${ }^{[4]}$. Many scholars have researched the development and elements constitution of characteristic towns, which is of great significance in enriching the significance of characteristic towns.

\subsection{Significance of the construction of a characteristic town}

As a novel innovation, the role characteristic towns are not well known for the people. Therefore, scholars have conducted an in-depth exploration of the value and significance of the construction of characteristic towns.

In industry, characteristic towns have the role of accelerating industrial innovation and upgrading, optimizing industrial layout, and promoting the sustainable development of local industries. With the new concept of innovation, green technologies, openminded, humanity, and flexible and innovative enterprise growth, characteristic towns can also accumulate highend production factors to enhance innovation and brand competitiveness, and at the same time enhance industrial connotation through the exploration of local historical and cultural elements to achieve the mutual integration of both industrial orientation and cultural connotation.

In regional development, the significance of characteristic towns is to enhance regional economic growth, promote industrial clustering and economic vitality, and enhance regional cultures. Characteristic towns break the boundaries of administrative units, providing a wide space for coordinated regional economic development. According to Shihao Sheng, a characteristic town is a new form of industrial organization that integrates the innovation, production, sales and service of unique industries. It is highly integrated into various development factors, which accelerates the transformation and development of regional industries ${ }^{[5]}$.

As a national strategy, the construction of small towns is an important element in connecting the city and the countryside. The current research on characteristic towns is mostly focused on the theoretical elaboration at the macro level yet it is lack of a systematic theoretical framework. The deepening of the research in the planning and construction of characteristic towns also play a great role in building the theoretical framework of the characteristic small (city) town system.

\section{Theories and Research Practices of Foreign Characteristic Town}

\subsection{Relevant theoretical studies}

Although there is no such concept of a characteristic town in oversea, its research on small towns has been involved for a long time, and the theoretical research has been relatively mature. From the analysis of related theories, it can be seen that most of the research is based on the theory of urban development, which focus on history and humanities, environment and society, sustainable development and other fields to carry out specific research for small towns.

In the 19th century, the British were trying to find a living environment that combined the advantages of urban and rural areas due to the deterioration of the urban environment ${ }^{[6]}$. Howard initiated the theory of "Garden Cities", designing a kind of functional selfsufficiency, beautiful living environment, convenient transportation of small towns, urban-rural integration model of development to crack the social structure of urban-rural separation ${ }^{[7]}$. In addition to the "Garden 
cities" theory, in the 1920 s, in response to the problems facing in town-building, British architects introduced the concept of satellite cities, emphasizing the satellite function of small towns to central cities. After World War II, the British government initiated a program of new towns, emphasizing the work-life balance in small towns. These theories and initiatives have stimulated the vitality of small towns, greatly promoted the development of small towns in Europe and the United States, and played an important role in the construction of China's characteristic small towns and the exploration of integrated urban and rural development ideas. The theory of "industrial clusters" was first proposed by Michael Porter, who argued that the sharing of resources and collaborative division of labour among enterprises can reduce operating costs to achieve considerable economy of scale ${ }^{[8]}$. From the feature of the characteristic town, it mainly forms an industrial cluster based on a certain dominant industry. The characteristic town is a spatial collection of industries, and its construction and development must be based on the advantages of its special industries, while the theory of "industrial clusters" provides the theoretical support for the construction of characteristic towns and provides a scientific theoretical basis to drive the regional economy ${ }^{[9]}$.

\subsection{Research on the Practice of Foreign Characteristic Towns}

Unique positioning is the distinctive feature of foreign small towns, and the construction of small towns is also relatively mature and perfect, and the emergence of various types of small towns has provided valuable experience and reference for the construction of China's characteristic towns.

Wolfsburg is a famous German car town where the headquarters of Europe's largest car manufacturer, Volkswagen Group, is located. By promulgating relevant legal system and providing technical support, the government has created a space for the development of automobile manufacturing research and development, and successfully built a brand of characteristic town featuring automobile manufacturing, automobile research and development, large-scale automobile production, industrial production packages, lifestyle and tourism experience ${ }^{[10]}$.

The most well-known of the foreign tech towns is Silicon Valley, and there are several very critical elements to its success. Firstly, the world-renowned universities around Silicon Valley have formed close partnerships with local businesses. Secondly, Silicon Valley's strong marketing and drive for innovation have caused its success. Finally, excellent industrial production and infrastructure support also support the long-term stable development of Silicon Valley.

Known as the "Hedge Fund Capital", the small town of Greenwich has attracted more than 500 hedge fund companies with its advantages of rapid internet speed and location. In addition, the town's beautiful environment, convenient infrastructure and transportation, and excellent living environment have attracted many high-quality talents, while favourable tax policies are also the reason for many enterprises and talents to settle down.

Annecy is known as the most beautiful town in the French Alps. Besides utilizing its natural resources, the full exploitation of historical and cultural resources, the vigorous development of tourism, culture and sports industries have driven the development of the town. Since the tourism industries are linked to many aspects, it is also necessary to fully promote the development of other supporting industries besides focusing on the main tourism industries.

The development of characteristic towns in Western countries has been accumulated over a long period, and their success is no coincidence. They share many common features, such as a long history and distinctive characteristics, developed economy, unique industries; beautiful and completeness of the environment, which is worth learning from our country. First of all, Western governments actively guide the development of small towns through innovative ideas and various policies. The technologies, policies, and budgets play a vital supporting role in the construction of small towns. Secondly, accurate industrial positioning is also the key to the core competitiveness of a characteristic town, focusing on unique industries and creating a complete ecological chain of characteristic industries to ensure the town's distinctiveness. Then, the utilization of historical, cultural resources and protection of the environment is the link that cannot be neglected in the construction of a characteristic town, which is the most unrepeatable resource of every characteristic town.

\section{Challenges and Countermeasures for Domestic Characteristic Town Construction}

\subsection{Challenges}

Compared with the successful experience of developed countries in the construction of characteristic towns, the practical achievements of local characteristic towns are more worthy of our reflection. Most scholars take 
Zhejiang's characteristic town construction experience as a research reference, and the whole country has also followed Zhejiang's experience to launch characteristic town planning and construction. After 5 years of development, the construction of a characteristic town has been successful. Characteristic towns conform to the development requirements under the new economic normal and have an excellent development, but they also encounter some problems in the current development.

\subsubsection{Unclear positioning of industries' specialities}

The differences in geography, culture, economy, and industry between different towns have created the characteristics of each town and determined the differences in the development positioning and planning of the town. Scholars have studied the industrial types of characteristic town from different perspectives, which plan and develop the town accordingly. Based on the town's unique resources, social needs, economy, ecology and long-term layout, Xindong Yu divided the industries in the characteristic town into three categories, which are the combination of resource endowment, social demands, and resource demands, that provides ideas for industrial positioning[11]. The other scholars have proposed classification methods from the perspectives of the nature of the industrial base, industrial driving force and industrial output, but no relatively unified and perfect industrial classification has been formed so far at the policy level. If the positioning of special industries is not clear, it will be difficult to build a special industrial system and space on which the town can survive, and the town will lose its core competitiveness in the development.

\subsubsection{Insufficient Development Momentum}

In the early stage of promotion of characteristic towns, the whole country started the construction from top to bottom. Some regions do not take into account the actual situation, or, to cope with higher-level inspections, do not explore in-depth into the characteristic connotations and the objectives. They apply the development patterns of other small towns, rashly and quickly starting planning and construction to obtain policy and financial support. This leads to various practical problems in the later stages of construction and hampering the development of small towns.

\subsubsection{Inadequate construction system}

Regarding the construction of the characteristic town, the country and provinces have also issued many guiding documents for the construction of characteristic towns, but many other towns lack systematic in-depth research, resulting in vague positioning and lack of unique characteristics. Those reasons are the lack of experience in small-town planning and construction techniques, absurd small town management and operation, and unscientific development and construction patterns in our country. The problems are embodied in the following aspects: The town has no highlights and lacks characteristics, the functional space is a patchwork and separated, lacking integration, insufficient cultural excavation and lacks connotation.

\subsection{Ideas for countermeasures}

Demonstrating its unique features is the basis of a characteristic town. The process of construction requires the builder to delve into industries with developmental advantages and potential. Developmental conditions and foundations vary from province to province and region to region, and the leading industries should be identified on the premise of local resource advantages. In the layout planning, aside from precise positioning and unique characteristics, it is also necessary to allocate the spatial layout of the land, implement infrastructure supporting constructions, overall arrangement and reasonable planning. To achieve the sustained development of the town, there are several specific areas.

Promote industrial clustering and build local brands. Relying on the leading industries, we will promote the formation of industrial clusters in the region, potentiate the advantages and characteristics of each enterprise, develop a high degree of integration, upscale the industrial development and boost industrial competitiveness. Strengthen innovation and branding to enhance brand awareness and make unique industries popular in the town.

Establishing a "people-oriented" development mindset and avoid the development model of copying and imitation. In terms of spatial organization, the focus on intensification and flexibility, reflect the scale and characteristics of the town, abolish "image projects", huge demolition and construction, and reflect the new face of the town through planning and design. At the same time, the town should focus on the actual needs of the town's residents, industrial population and explore development models that continue to attract talents.

Strengthening policy support and guidance. Strengthen the government's policy, leadership role, and give full support to land use, finance, talent support and other policies, and promote the sustained development of the industry. Active exploration and innovation of the policies of characteristic town and the integration of various resources provide better services and 


\section{development environment for enterprises.}

\section{References}

[1] Zhao PP, Ding Y. Characteristic town creation and its planning and design features analysis in Zhejiang province $[\mathrm{J}]$. Planner, 2016, 32(12): 57-62.

[2] Zhang LP. Analysis of the theoretical and practical context of the development of China's characteristic small towns[J]. Research World, 2018(6): 3-7.

[3] Wei LB, Shi XJ. Some Reflections and Suggestions on the Construction of Zhejiang Special Town[J]. Zhejiang Social Science, 2016(3): 28-32.

[4] Wang XZ. Characteristics and Generalities of Characteristic Small Towns[J]. Zhejiang Social Science, 2016(3): 46-47.

[5] Sheng SH, Zhang WM. Characteristic town: a form of industrial space organization[J]. Zhejiang Social Science, 2016(3): 3638 .
[6] Lu WF.A preliminary exploration of rural urbanization in Britain since 1851- taking small towns as a perspective[J]. Social Science, 2017(4): 153-167.

[7] Gao XG, Lu QH. The ideological value of Howard's idyllic city theory and its practical revelation--Rereading the Idyllic City of Tomorrow[J]. Planner, 2013, 29(11): 105-108.

[8] Yang ZY, Cai JM, Fu CW. The inspiration of industrial cluster theory to urban planning construction in China[J]. Urban Planning, 2012, 36(12): 60-68.

[9] Li PX. Evaluation of the development level of Foshan science and technology innovation special town cluster based on diamond model[J]. Business Economics, 2018(5): 37-38+79.

[10]Li L. The triumph of small industrial towns: the winning secret of Germany's industrial townships[J]. Beijing Planning and Construction,2017(03):24-30.

[11]Yu XD. The industrial positioning of a special town[J]. Zhejiang Economy, 2016(8): 21. 